\title{
Letter to the Editor: Does Degenerative Lumbar Spine Disease Influence Femoroacetabular Flexion in Patients Undergoing Total Hip Arthroplasty?
}

\author{
Ping-Heng Lan MD, PhD, Jun Zhang MD, Zhi-Heng Liu MD, \\ Hai-Qiang Wang MD, PhD
}

To the Editor,

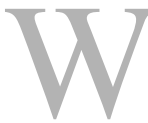

e have read the study by Esposito and colleagues with great interest. We would like to applaud the authors for

(RE: Esposito CI, Miller TT, Kim HJ, Barlow BT, Wright TM, Padgett DE, Jerabek SA, Mayman DJ. Does Degenerative Lumbar Spine Disease Influence Femoroacetabular Flexion in Patients Undergoing Total Hip Arthroplasty? Clin Orthop Relat Res.

[Published online ahead of print March 28, 2016]. DOI: 10.1007/s11999-016-4787-2).

The authors certify that they, or any member of their immediate families, have no funding or commercial associations (eg, consultancies, stock ownership, equity interest, patent/licensing arrangements, etc) that might pose a conflict of interest in connection with the submitted article. All ICMJE Conflict of Interest Forms for authors and Clinical Orthopaedics and Related Research ${ }^{\circledR}$ editors and board members are on file with the publication and can be viewed on request.

The opinions expressed are those of the writers, and do not reflect the opinion or policy of $C O R R^{\circledR}$ or The Association of Bone and Joint Surgeons ${ }^{\mathbb{R}}$. meticulously linking lumbar disc degeneration (LDD) with THA. After analyzing EOS spine-to-ankle lateral radiographs of 325 patients undergoing THA, they found a slight difference in hip flexion between patients with LDD and those without LDD. Their findings indicate that arthroplasty surgeons should take LDD into account when performing THA.

Accumulating evidence indicates that global alignment [2], sagittal vertical axis

P.-H. Lan MD, PhD,

H.-Q. Wang MD, PhD ( $ه)$

Department of Orthopaedics, Xijing

Hospital, Fourth Military Medical

University, 127 Changle Western Road,

Xi' an 710032, China

e-mail: hqwang@fmmu.edu.cn;

drwanghq@163.com

J. Zhang MD

Department of Orthopaedics, Baoji

Municipal Central Hospital, Baoji,

Shaanxi, China

Z.-H. Liu MD

Department of Orthopaedics, Xi' an Air Force Hospital, Xi' an, China
[13], and global sagittal axis [5] have been accepted as important parameters for body balance. Sagittal balance is linked with sagittal spinopelvic parameters, including pelvic incidence, pelvic tilt, and sacral slope [15]. In a sense, the pelvis can be considered another three-dimensional caudal element of the spine [6], and its position-pelvic incidence-both influences and is inextricably linked with that of the spine [8]. These concepts are critical both for hip arthroplasty surgeons and for surgeons who treat adult spinal deformity [15].

In their study, Esposito and colleagues evaluated spinopelvic alignment using sacral slope, lumbar lordosis, and proximal femur angles, instead of pelvic incidence. In fact, pelvic incidence is an individualized morphological parameter not affected by posture and LDD. If Esposito and colleagues considered global spinopelvic alignment in their study, the results might be more convincing.

Regarding the impact of spinal alignment on THA, Buckland and colleagues 
[3] reported that patients with spinopelvic malalignment were at risk for acetabular component anteversion during THA. They evaluated pelvic incidence, pelvic tilt, and sacral slope, lumbar lordosis, T1 pelvic angle, sagittal vertical axis, and thoracic kyphosis. Their results suggest that spinopelvic alignment is important both for spine surgeons and for hip arthroplasty surgeons.

In the past, MRI has been regarded as the gold standard for evaluating LDD [10]. A number of grading schemes have been developed since, including the five-grade Pfirrmann scheme [10], and four-grade Schneiderman system [12]. Esposito and colleagues graded LDD using a ninepoint classification system. Since LDD is characterized by loss of water and proteoglycans in the disc, those kinds of changes may be best seen on T2weighted MRI images [4, 9, 14]. Other parameters reflective of LDD may also best be evaluated using MRI, such as loss of disc height [7] and changes to the appearance of the endplates, which can be seen with newer techniques like DCE-MRI $[1,11]$. In light of that, we wonder whether grading of LDD might be more accurate and reasonable using MRI rather than radiographs.

Acknowledgments This work was supported by the National Natural Science Foundation of China 81270028 and 81572182.

\section{References}

1. Arpinar VE, Rand SD, Klein AP, Maiman DJ, Muftuler LT. Changes in perfusion and diffusion in the endplate regions of degenerating intervertebral discs: a DCE-MRI study. Eur Spine J. 2015;24:24582467.

2. Bess S, Protopsaltis TS, Lafage V, Lafage R, Ames CP, Errico T, Smith JS; International Spine Study Group. Clinical and radiographic evaluation of adult spinal deformity. Clin Spine Surg. 2016;29:6-16.

3. Buckland AJ, Vigdorchik J, Schwab FJ, Errico TJ, Lafage R, Ames C, Bess S, Smith J, Mundis GM, Lafage V. Acetabular anteversion changes due to spinal deformity correction: Bridging the gap between hip and spine surgeons. J Bone Joint Surg Am. 2015;97:1913-1920.

4. Chen YF, Zhang YZ, Zhang WL, Luan GN, Liu ZH, Gao Y, Wan ZY, Sun Z, Zhu S, Samartzis D, Wang CM, Wang HQ, Luo ZJ. Insights into the hallmarks of human nucleus pulposus cells with particular reference to cell viability, phagocytic potential and long process formation. Int J Med Sci. 2013;10:1805-1816.

5. Diebo BG, Lafage V, Schwab F. Pelvic incidence: The great biomechanical effort. Spine. 2016;41:S2122.

6. Dubousset J. Three-dimensional analysis of the scoliotic deformity. In: Weinstein SL, ed. The Pediatric Spine: Principles and Practice. Raven Press Ltd., New York, NY:1994;479-496.
7. Jarman JP, Arpinar VE, Baruah D, Klein AP, Maiman DJ, Muftuler LT. Intervertebral disc height loss demonstrates the threshold of major pathological changes during degeneration. Eur Spine J. 2015;24:19441950.

8. Legaye J, Duval-Beaupere G, Hecquet J, Marty C. Pelvic incidence: a fundamental pelvic parameter for three-dimensional regulation of spinal sagittal curves. Eur Spine J. 1998;7:99-103.

9. Li XK, Wu ZG, Ding T, Wang HQ. Revisiting the nomenclature and grading schemes for disc degeneration: issues to be solved. Spine J. 2015;15:2594-2595.

10. Pfirrmann CW, Metzdorf A, Zanetti M, Hodler J, Boos N. Magnetic resonance classification of lumbar intervertebral disc degeneration. Spine. 2001;26:1873-1878.

11. Samartzis D, Borthakur A, Belfer I, Bow C, Lotz JC, Wang HQ, Cheung KM, Carragee E, Karppinen J. Novel diagnostic and prognostic methods for disc degeneration and low back pain. Spine J. 2015;15:1919-1932.

12. Schneiderman G, Flannigan B, Kingston S, Thomas J, Dillin WH, Watkins RG. Magnetic resonance imaging in the diagnosis of disc degeneration: correlation with discography. Spine. 1987;12:276-281.

13. Wan ZY, Song F, Sun Z, Chen YF, Zhang WL, Samartzis D, Ma CJ, Che L, Liu X, Ali MA, Wang HQ, Luo ZJ. Aberrantly expressed long noncoding RNAs in human intervertebral disc degeneration: A 
Letter to the Editor

microarray related study. Arthritis Res Ther. 2014;16:465.

14. Wang HQ, Samartzis D. Clarifying the nomenclature of intervertebral disc degeneration and displacement: from bench to bedside. Int $J$ Clin Exp Pathol. 2014;7:1293-1298.

15. Yamato Y, Hasegawa T, Kobayashi S, Yasuda T, Togawa D, Arima H, Oe S, Iida T, Matsumura A, Hosogane N,
Matsumoto M, Matsuyama Y. Calculation of the target lumbar lordosis angle for restoring an optimal pelvic tilt in elderly patients with adult spinal deformity. Spine. 2016;41:E211-217. 